(2) Open Access Full Text Article

\title{
Imaging late capsular bag distension syndrome: an anterior segment optical coherence tomography study
}

This article was published in the following Dove Press journal:

Clinical Ophthalmology

5 September 2012

Number of times this article has been viewed

Yar Li Tan ${ }^{1,2}$

Lakshmanasamudram S

Mohanram'

Seng $\mathrm{Ei} \mathrm{Ti}^{1,2}$

Tin Aung ${ }^{1-3}$

Shamira Perera ${ }^{1,2}$

'Singapore National Eye Centre, ${ }^{2}$ Singapore Eye Research Institute, ${ }^{3}$ National University of Singapore,

Yong Loo Lin School of Medicine,

Buona Vista, Singapore
Correspondence: Shamira Perera Singapore National Eye Centre, II Third Hospital Avenue, Singapore 16875I, Singapore

Tel +65 62277255

Fax +6562263395

Email shamira.perera@snec.com.sg
Background: Anterior segment optical coherence tomography (ASOCT) was used to categorize and provide insights into the etiology of capsular bag distension syndrome (CBDS).

Methods: A prospective review was undertaken of 10 cases who presented with signs of late CBDS 5-11 years after uneventful phacoemulsification with in-the-bag posterior chamber intraocular lens implantation.

Results: All 10 patients presented with a milky collection within the distended capsular bag without raised intraocular pressure or a shallow anterior chamber. ASOCT was used to confirm the diagnosis in all cases, and a hyperintense signal was seen in the space between the posterior chamber intraocular lens and the posteriorly bowed posterior capsule. The continuous curvilinear capsulorhexis was measured to be between $3.18 \mathrm{~mm}$ and $4.70 \mathrm{~mm}$. Three cases had uncorrected visual acuity better than 6/12. Uncomplicated Neodymium-doped Yttrium Aluminium Garnet (Nd:YAG) posterior capsulotomy was performed in eight patients, with no resulting change in the intraocular lens position (measured by ASOCT) or subjective refraction.

Conclusion: Our study showed that ASOCT is a useful modality to differentiate this condition clearly from posterior chamber intraocular lens opacification and to investigate its causation. Nd:YAG posterior capsulotomy proved to be a safe and successful treatment for late CBDS with no change in biometric or refractive parameters.

Keywords: anterior segment optical coherence tomography, capsular bag distension syndrome, YAG capsulotomy

\section{Introduction}

Capsular bag distension syndrome (CBDS) is a rare complication of phacoemulsification with an anterior continuous curvilinear capsulorhexis and in-the-bag intraocular lens implantation. It may also be associated with a can-opener type capsulorhexis and sulcus-implanted intraocular lens. ${ }^{1,2}$ In 1990, Davison first described cases of early postoperative CBDS with a shallow anterior chamber, elevated intraocular pressure, and induced myopia from the anterior shift of the intraocular lens. ${ }^{3}$ Miyake et al reclassified CBDS into intraoperative, early postoperative, and late postoperative CBDS based on the heterogeneity of the clinical features in these cases. ${ }^{4}$ Late CBDS has also been termed liquefied after-cataract ${ }^{5}$ or capsulorhexis-related lacteocrumenasia. ${ }^{6}$

We pooled 10 highly similar cases presenting with late CBDS. Uniquely in all our patients, anterior segment optical coherence tomography (ASOCT, Visante, Carl Zeiss Meditec, Dublin, CA) was used to categorize correctly and elucidate the etiology of this subtype of CBDS. Our study adhered to the tenets of the Declaration of Helsinki. 


\section{Case series}

All 10 patients had a history of uncomplicated phacoemulsification with in-the-bag intraocular pressure implantation. This occurred 5-11 years before presentation with CBDS (Table 1). Seven patients presented with insidious blurring of vision while three patients were asymptomatic and diagnosed incidentally during routine follow-up. In all patients, slit-lamp examination revealed a quiet anterior chamber with normal intraocular pressure and a characteristic milky fluid trapped within the capsular bag. ASOCT confirmed the diagnosis of CBDS in all 10 cases. Eight of 10 patients underwent an uneventful Nd-YAG posterior capsulotomy. Figure 1A and B shows slit-lamp photographs of a case before and after Nd-YAG posterior capsulotomy, and Figure 1C shows an ASOCT image demonstrating a hyperintense signal within the capsular bag.

\section{Discussion}

ASOCT was useful in confirming the diagnosis of CBDS in all our cases, because a hyperintense signal was seen in the space between the intraocular lens and the posterior capsule.

Posterior capsular opacification was notably absent in our cases in contrast with the series by Pinarci et al where CBDS remained undiagnosed for a long time before posterior capsular opacification developed. ${ }^{7}$ The use of ultrasound biomicroscopy and Scheimpflug imaging to aid in the diagnosis of CBDS has also been reported. ${ }^{8-10}$ Murat et al compared the use of ultrasound biomicroscopy and Scheimpflug imaging in two patients and found that ultrasound biomicroscopy seemed to be superior to Scheimpflug imaging in eyes with extremely distended capsular bags because the latter failed to visualize the posterior capsule and also had an error in estimation of the anterior chamber depth. ${ }^{8}$ Lau et al reported ASOCT findings in a case of early CBDS, demonstrating a shallow anterior chamber and distended capsular bag with a large distance between the intraocular pressure and posterior capsule. ${ }^{11}$ In our study, ASOCT was used to estimate the size of the continuous curvilinear capsulorhexis and the anterior chamber depth quantitatively (pre-YAG and post-YAG capsulotomy). ASOCT is technically easier to perform because it is noncontact and done with the patient in the upright position, as compared with ultrasound biomicroscopy which requires immersion and the patient to be in a supine position.

Management of CBDS depends largely on the presenting visual acuity. Three cases had uncorrected visual acuity better than $6 / 12$ and one retained good best-corrected visual acuity of $6 / 6$ beyond one year of follow-up. In the presence

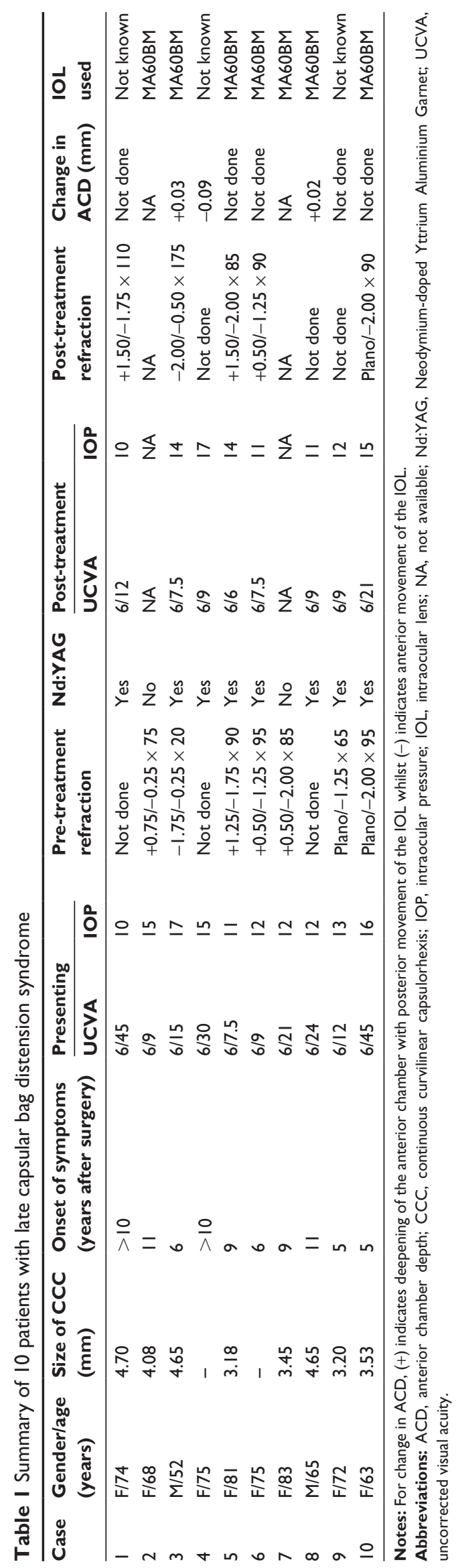




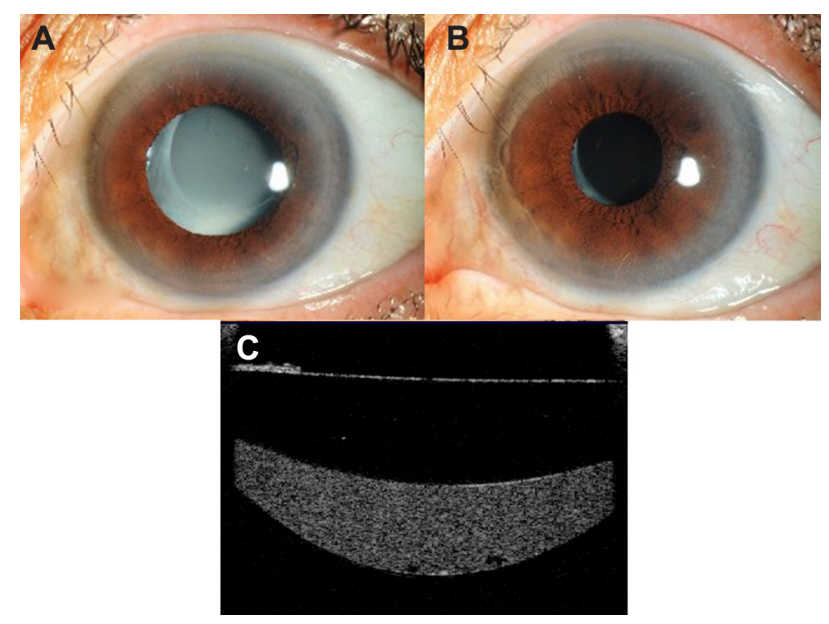

Figure I (A) Slit-lamp photograph showing characteristic milky fluid within the capsular bag in a patient with late capsular bag distension syndrome. (B) Slit-lamp photograph showing resolution of the milky fluid post-YAG capsulotomy. (C) Anterior segment optical coherence tomography showing the hyperintense signal within the capsular bag.

of a distended capsular bag trapped with milky fluid, there could be technical difficulty in focusing of the Nd:YAG laser on the posterior capsule, hence leading to failure, which may then require surgical drainage of the trapped fluid. ${ }^{12}$ However, this problem was not encountered in our series, and Nd-YAG posterior capsulotomy was safely performed in eight of our patients with no complications, such as an intraocular pressure spike or excessive inflammation. Kollias et al reported a case of Propionibacterium acnes in late $\mathrm{CBDS},{ }^{13}$ but in our series, the absence of vitreous inflammation post-YAG posterior capsulotomy indicated that there was no deleterious infective or inflammatory etiology. Of note, there were no cases of retinal detachment seen in our patients after YAG posterior capsulotomy. Whilst YAG posterior capsulotomy remains a relatively simple treatment option, it can still be associated with various risks and complications. Hence, it may be prudent to observe the patient until the onset of visually significant symptoms.

In four patients with pre-YAG and post-YAG capsulotomy refractions performed, there were no refractive changes noted. This finding is similar to that in the series by Pinarci et al. ${ }^{7}$ In our series, we were also able to use ASOCT to measure the change in anterior chamber depth pre-YAG and post-YAG capsulotomy, and it similarly showed an insignificant change of less than $0.1 \mathrm{~mm}$ in anterior chamber depth measurements, indicating minimal biometric change post-YAG capsulotomy (Table 1).

In most cases of CBDS, be they early or late, the size of continuous curvilinear capsulorhexis tends to be small, ${ }^{9}$ and tight adherence to the anterior surface of the intraocular pressure prevents escape of intracapsular fluid. In our series, ASOCT measured the horizontal diameter of the continuous curvilinear capsulorhexis to be in the range of 3.18-4.70 mm, thus corroborating these observations. However, because there are no longitudinal measurements, one cannot confirm whether there had been any capsular contraction.

In conclusion, our study showed that ASOCT is a quick and easy method of imaging the anterior segment to differentiate CBDS clearly from posterior chamber intraocular lens opacification. It can also aid in diagnosis of late CBDS, especially when the milky fluid is not as obvious. Common characteristics seen in our cases were the relatively small continuous curvilinear capsulorhexis in all cases and acrylic intraocular pressures (MA60BM) in seven of 10 cases. YAG posterior capsulotomy was safe and yielded excellent visual results in all cases, with minimal biometric or refractive changes.

\section{Disclosure}

TA has received research support, travel funding, and honoraria from Carl Zeiss Meditec and Alcon, and is a consultant to Alcon. SA Perera has received honoraria from Carl Zeiss Meditec.

\section{References}

1. Agrawal S, Agrawal J, Agrawal TP. Complete capsular bag distension syndrome. J Cataract Refract Surg. 2000;26(9):1417-1418.

2. Miyake K, Ota I, Miyake S, Terasaki H. Capsular block syndrome with external blockage of the capsular opening by a ciliary sulcus fixated posterior chamber lens. Am J Ophthalmol. 1999;127(5): 605-607.

3. Davison JA. Capsular bag distension after endophacoemulsification and posterior chamber intraocular lens implantation. $J$ Cataract Refract Surg. 1990;16(1):99-108.

4. Miyake K, Ota I, Ichihashi S, Miyake S, Tanaka Y, Terasaki H. New classification of capsular block syndrome. J Cataract Refract Surg. 1998;24(9):1230-1234.

5. Miyake K, Ota I, Miyake S, Horiguchi M. Liquefied after-cataract: a complication of continuous curvilinear capsulorhexis and intraocular lens implantation in the lens capsule. Am J Ophthalmol. 1998;125(4): 429-435.

6. Eifrig DE. Capsulorhexis-related lacteocrumenasia. J Cataract Refract Surg. 1997;23(3):450-454.

7. Pinarci EY, Bayar SA, Sizmaz S, Canan H, Yilmaz G. Late capsular block syndrome presenting with posterior capsule opacification. J Cataract Refract Surg. 2012;38(4):672-676.

8. Kucukevcilioglu M, Hurmeric V, Erdurman FC, Ceylan OM. Imaging late capsular block syndrome: ultrasound biomicroscopy versus Scheimflug camera. J Cataract Refract Surg. 2011;37(11):2071-2074.

9. Theng JTS, Jap A, Chee SP. Capsular block syndrome: a case series. $J$ Cataract Refract Surg. 2000;26(3):462-467.

10. Jain R, Grewal D, Gupta R, Grewal SP. Scheimflug imaging in late capsular bag distension syndrome after phacoemulsification. Am J Ophthalmol. 2006;142(6):1083-1085.

11. Lau FH, Wong AL, Lam PT, Lam DS. Photographic essay. Anterior segment optical coherence tomography findings of early capsular block syndrome. Clin Experiment Ophthalmol. 2007;35(8): 770-771. 
12. Qu J, Bao Y, Li M, Zhao M, Li X. Surgical management of late capsular block syndrome. J Cataract Refract Surg. 2010;36(10): 1687-1691.
13. Kollias AN, Vogel MA, de Kaspar HM, Lackerbauer CA, Grueterich M. Propionibacterium acnes in capsular bag distension syndrome. $J$ Cataract Refract Surg. 2010;36(1):167-169.

\section{Publish your work in this journal}

Clinical Ophthalmology is an international, peer-reviewed journal covering all subspecialties within ophthalmology. Key topics include: Optometry; Visual science; Pharmacology and drug therapy in eye diseases; Basic Sciences; Primary and Secondary eye care; Patient Safety and Quality of Care Improvements. This journal is indexed on
PubMed Central and CAS, and is the official journal of The Society of Clinical Ophthalmology (SCO). The manuscript management system is completely online and includes a very quick and fair peer-review system, which is all easy to use. Visit http://www.dovepress.com/ testimonials.php to read real quotes from published authors. 